\title{
Organização Intermunicipal: estudo de caso do Consórcio Público de Saúde na Região Fronteira Noroeste do Rio Grande do Sul
}

Nelson José Thesing

Universidade Regional do Noroeste do Estado do Rio Grande do Sul

\section{Sérgio Luis Allebrandt}

Universidade Regional do Noroeste do Estado do Rio Grande do Sul

\section{Mauro Alberto Nuske}

Universidade Regional do Noroeste do Estado do Rio Grande do Sul

Nedisson Luis Gessi

Universidade Regional do Noroeste do Estado do Rio Grande do Sul

\section{Resumo}

O artigo busca compreender a organização intermunicipal do Consórcio Público de Saúde Fronteira Noroeste do Rio Grande do Sul, tendo como meta pesquisar os serviços de saúde de média e alta complexidade, em 25 municípios, ao trilhar os caminhos da abordagem qualitativa, análise de conteúdo, interpretando os dados coletados pelo questionário, os documentos acessados e as verificações teóricas. Isso significa identificar e analisar as relações entre a saúde e as estruturas de saúde que possam contribuir no desenvolvimento da região, onde as dimensões da saúde se apresentam como um direito e com capacidade de mobilizar recursos para o desenvolvimento do ambiente de saúde nos municípios e qualificar a área na busca de melhores condições de vida da população. Para responder aos desafios propostos, utilizamos a coleta de dados, por um questionário com questões abertas, enviado para o gestor do consórcio e para três secretários municipais de saúde consorciadas. As respostas apresentam a importância do consórcio, com a ampliação dos serviços, a presença de profissionais para responder aos serviços de média e alta complexidade, bem como a redução dos custos em $25 \%$. Como desafios a serem superados, destacamos a qualificação da estrutura funcional do consórcio, especialmente a matriz administrativa. Por fim, a pesquisa aponta uma experiência rica do consórcio, ao ampliar o atendimento das necessidades na área da saúde nos 25 municípios, ao promover um 
ambiente de cooperação e ao potencializar as políticas públicas na região Fronteira Noroeste.

Palavras-chave: Serviços Públicos. Consórcios Municipais. Políticas Públicas.

\title{
Intermunicipal Consortia: Case Study of the Public Health Consortium in Northwest Border of RS
}

\begin{abstract}
The study analyzes an intermunicipal organization, the Public Health Consortium Northwest Border of Rio Grande do Sul - COFRON, having as its main purpose to investigate the health services of medium and high complexity, in 25 cities, working with the qualitative, exploratory and descriptive approach, content analysis, interpreting collected data from bibliographic, documental and empirical research. This means identify and analyze the relationships between health and development, the dimensions as a right. In order to answer the proposed challenges, data collection was used, the interview applied as a questionnaire with open questions with one of the consortium managers, in three municipal health secretaries, with strong indications of the importance and relevance of the consortium, on enlarging services and professionals in medium and high complexity, as well as reducing costs by $25 \%$. As aspects to improve, the qualification of the functional structure of the consortium is highlighted, especially the management as a whole. Finally, the research points to a successful experience of the consortium, by expanding the needs of the 25 cities, by promoting an environment of cooperation and by enhancing public health policies.
\end{abstract}

Keywords: Intermunicipal consortia. Public Health. Public Policies.

\section{Organización Intermunicipal: Estudio de Caso del Consorcio Público de Salud en la Frontera Noroeste do RS}

\section{Resumen}

El estudio verifica una organización intermunicipal, el Consórcio Público de Saúde Fronteira Noroeste do Rio Grande do Sul - COFRON, teniendo como objetivo investigar los servicios de salud de media y alta complejidad, en 25 ciudades, al trabajar con enfoque cualitativo, exploratorio y descriptivo, análisis de contenido, interpretando los datos colectados, de la investigación bibliográfica, documental y empírica. Lo que significa identificar y analizar las relaciones entre la salud y el desarrollo, las dimensiones de salud como un derecho. Para contestar a los desafíos propuestos, utilizamos la recolección de datos, la entrevista aplicada en forma de cuestionarios con cuestiones abiertas, con uno de los gestores del consorcio, en tres secretarias municipales de salud consorciadas, con indicativos fuertes de la importancia y relevancia del consorcio, al ampliar los servicios y profesionales en media y alta complejidad, así como la reducción de costos un $25 \%$. Como aspectos a mejorar, destacamos la calificación de la estructura funcional del consorcio, especialmente la gestión como un todo. Por último, la investigación apunta una experiencia exitosa del consorcio, al ampliar la atención de las necesidades de los 25 municipios, al promover un ambiente de cooperación y potenciando las políticas públicas en la salud.

Keywords: Consorcios intermunicipales. Salud pública. Políticas públicas. 


\section{Introdução}

A organização intermunicipal, o Consórcio Público de Saúde, integra os desafios do desenvolvimento, nas dimensões econômicas, ao potencializar investimentos nas estruturas, no campo social, ao ampliar a prestação dos serviços, a qualificação profissional, o que significa, para os municípios e as regiões, a busca permanente de melhores condições de vida da população. Potencializam os empreendimentos locais, a atração de investimentos externos, a manutenção de profissionais na região, bem como os recursos provenientes de outros municípios, regiões, Estado.

Para tanto, a articulação e formalização de parcerias tem se tornado uma prática cada vez mais recorrente, independente da categoria administrativa ou do setor, possibilitando o acesso a recursos a partir da união de interesses e o poder de barganha, tanto em termos de negociação na aquisição dos produtos quanto na prestação dos serviços. Assim, os consórcios têm-se apresentado como uma alternativa para que municípios se organizem e se fortaleçam, principalmente os pequenos municípios, reduzindo custos e oportunizando a ampliação das capacidades que, individualmente, geralmente são reduzidas.

Corroboram essa matriz administrativa Scomparini e Zaninelo (2010) ao destacarem que os gestores municipais aderiram a essa estratégia para potencializar as ações e serviços de saúde oferecidos nos municípios e a estratégia de organização regional na área da saúde. Ainda, os Consórcios Intermunicipais de Saúde fortalecem a matriz administrativa do setor, visando maior eficiência, racionalidade e qualidade na área da gestão pública.

Portanto o artigo investiga o Consórcio Público de Saúde Fronteira Noroeste do RS - Cofron, que integra 25 municípios, mais três municípios que não fazem parte da região, ao verificar a oferta de serviços de média e alta complexidade e sua interação como desenvolvimento regional.

\section{Metodologia}

No entender de Lovato (2013), a metodologia tem por finalidade o estudo dos métodos que poderão auxiliar na busca dos resultados e responder aos objetivos propostos da pesquisa. Assim, a investigação trabalha com a abordagem qualitativa, análise de conteúdo, pesquisa bibliográfica, documental e a coleta de informações oriundas do questionário.

Para Alves-Mazzotti e Gewandsznajder (1998), as pesquisas qualitativas oportunizam um enorme volume de dados que precisam ser organizados e compreendidos. Significa que, na medida em que os dados são coletados, o pesquisador necessita buscar informações, construindo interpretações e gerando novas questões, ou mesmo ampliar as anteriores, o que, por sua vez, desafia a buscar novas fontes, apontando um processo de sintonia fina, gerando novos conhecimentos.

O questionário foi elaborado com questões fechadas e abertas, aplicado para os gestores do consórcio, três secretárias de saúde. Significa a interpretação de um conjunto de perguntas, conforme Collis e Hussey (2005), o questionário é uma lista de perguntas que foram cuidadosamente elaboradas para extrair respostas 
confiáveis, tendo como objetivo descobrir o que um grupo selecionado de participantes faz, pensa ou sente. Dessa forma, foram coletadas as informações, pelo questionário, dos integrantes do Consórcio e de três Secretárias Municipais de Saúde para investigar a organização intermunicipal.

Para a interpretação dos resultados, trabalhamos com o método de pesquisa comparativa, de Andrade (1995), Lakatos e Marconi (1986). Esse caminho metodológico permite realizar comparações, interpretando semelhanças e diferenças nas respostas obtidas pelos gestores do Consórcio e as Secretárias Municipais de Saúde, bem como trabalhar com os referenciais teóricos e documentais. Conforme destacam Collis e Hussey (2005), a análise documental pode dizer muita coisa sobre os princípios e normas que regem o comportamento de um grupo e sobre as relações que se estabelecem entre diferentes subgrupos, que, neste estudo, significa verificar a organização intermunicipal, ou seja, o Consórcio Público de Saúde na Região Fronteira Noroeste do Rio Grande do Sul.

\section{Desenvolvimento e Cooperação}

No entender de Sausen (2012), desenvolvimento, por ser um termo complexo e dinâmico, no transcorrer das décadas, modificou-se, adaptou-se, transitando nas mais diversas áreas do conhecimento, desenvolvendo um caráter multidisciplinar. O desenvolvimento pode significar a busca do bem-estar social, econômico, cultural, a realização humana. Poderá ser um meio para a conquista da sustentabilidade, ao fazer o uso razoável de recursos da terra, preservando as espécies e o seu respectivo habitat natural.

Numa perspectiva mais ampla, pode-se estabelecer uma relação
muito próxima do conceito de desenvolvimento ao conceito de
transformação, na qual ocorrem modificações necessárias para um
melhor aproveitamento e aperfeiçoamento do espaço físico, dos
recursos humanos e dos meios disponíveis. Estas modificações
acabam por beneficiar toda uma comunidade, local ou regional,
promovendo desta forma o seu desenvolvimento. (SAUSEN, 2012,
p. 254).

Já para Bigaton e Maia (2016), desenvolvimento passa a ser uma ampliação sustentável (nos planos econômico, social e ambiental) da oferta e da apropriação de bens materiais e culturais por parte de uma determinada comunidade. Portanto, para os autores, o desenvolvimento endógeno e exógeno é definido pela origem da produção e bem-estar, sendo que a origem externa caracteriza-se pelo desenvolvimento exógeno e a origem interna, pelo endógeno.

No entender de Frantz (2010), o desenvolvimento é um fenômeno que não se dá no vazio, mas se apresenta na dinâmica social da economia, da política, da cultura, da educação. Significa que o processo social do desenvolvimento dialoga com as relações com o meio ambiente, com a natureza.

Para Dallabrida e Zimmermann (2009) o processo de desenvolvimento pode ser alicerçado pela cooperação com seus semelhantes, pela conjugação de esforços para atingir objetivos que, individualmente, não teria condições de atingir. Essa necessidade primária de cooperação poderá ser atendida por organizações. Essas 
organizações podem se constituir das mais variadas formas e tipos. Este estudo contempla o interesse pela organização pública, consórcio público.

Esse trilhar pelo consórcio estabelece relações com vários níveis de governo, - que poderá facilitar um ambiente de cooperação entre os escalões governamentais, entre governo e entidades públicas, entidades privadas e associações civis, entre entes federados (União, estados e municípios), entre países e até entre organizações supranacionais.

De acordo com Bergoc (2001), o processo associativo entre entidades públicas e privadas não lucrativas, intergovernamentais, do mesmo ou diferente escalão, põe em evidência a necessidade de envolvimento de entidades da sociedade civil de diferentes tipos e fazem emergir novos conceitos que buscam respostas para os problemas que o Estado dá mostras de que não poderá, ou não se interessa em resolvê-los.

\title{
3.1 Consórcios
}

Para Ribeiro e Costa (2000), a matriz administrativa e o regramento dos consórcios se apresentam como alternativas organizacionais para promover um maior grau de flexibilidade gerencial, seja na aquisição de equipamentos, na contratação de pessoal e na implementação de programas de incentivo. Dessa forma, podem ser caracterizados como organizações semipúblicas do setor saúde e que antecedem o próprio projeto das Organizações Sociais formuladas pelo governo federal [Brasil, 1995]. Representam, por outro lado, juntamente com as demais iniciativas cooperativadas, fundações privadas, entidades filantrópicas, organizações não governamentais, mudanças organizacionais marcantes na esfera pública, orientadas à resolução de problemas imediatos, porém de sustentabilidade incerta.

\begin{abstract}
Consórcio, do latim consortiu, implica a ideia de associação, ligação, união e, no âmbito das relações intermunicipais, nada mais apropriado do que a formação de entidades visando o estudo, o acompanhamento, o diagnóstico das soluções que, via de regra, envolvem municípios limítrofes e com problemas que se identificam numa ordem cada vez mais crescente, em função de forte demanda dos administrados. A formação de consórcio não obedece a uma única lógica, mas aos interesses e disponibilidades de uma dada região, conformando diversos modos de atuação e permitindo o seu aprimoramento, inclusão ou não de municípios, agrupamento de municípios que, pela lógica da proximidade, pode não pertencer ao estado/sede do consórcio. (LIMA, 2000, p. 986).
\end{abstract}

Na visão de Bigaton e Maia (2016), os consórcios se apresentam como uma estratégia administrativa e política, que viabiliza parcerias entre os agentes participantes. Também demonstra que a cooperação mútua de administrações regionalizadas permite que esses municípios articulem e planejem ações em benefício próprio e para a região. Essa forma cooperativa tende a sanar problemas com a capacidade técnica e financeira da região consorciada.

Para Tenório (2004), consórcios intermunicipais são entidades que reúnem diversos municípios para realização de ações conjuntas que, se fossem produzidas pelos municípios individualmente, não atingiriam os mesmos resultados ou teriam um gasto financeiro maior. Ainda destaca o autor que a participação de vários 
segmentos da sociedade nas discussões e na busca de soluções conjuntas efetiva estabelecimento de parcerias. Pode ser considerado, também, como uma divisão de poderes pela presença dos diversos segmentos e níveis de governo.

No entender de Cunha (2004), as experiências de consorciamento existentes ao longo da história foram ancoradas em duas modalidades: a organização de consórcios como associação civil, portanto sob as regras do direito privado, e os chamados consórcios administrativos. Permanecem críticas quanto à precariedade e à insegurança jurídica dos instrumentos de direito privado e a dificuldade para sua utilização por entes governamentais.

Do ponto de vista da ação dos governos municipais envolvidos, Calderan (2013, p. 157) destaca que a criação de consórcios públicos pode produzir resultados positivos de cinco tipos:

a) Aumento da capacidade de realização: os governos municipais podem ampliar o atendimento aos cidadãos e o alcance das políticas públicas por conta da disponibilidade maior de recursos e do apoio dos demais municípios.

b) Maior eficiência do uso dos recursos públicos: é o caso dos consórcios cuja função central é o compartilhamento de recursos escassos, de máquinas de terraplanagem a unidades de saúde ou unidades de disposição final de resíduos sólidos. O volume de recursos aplicados como investimento no consórcio e o custeio de sua utilização são menores do que a soma dos recursos que seriam necessários a cada um dos municípios para produzir os mesmos resultados.

c) Realização de ações inacessíveis a uma única prefeitura: a articulação de esforços em um consórcio pode criar condições para que seja possível atingir resultados que não seriam possíveis a nenhuma prefeitura isoladamente, ou mesmo à soma dos esforços individuais de cada uma delas. É o caso da aquisição de equipamentos de alto custo, o desenho de políticas públicas de âmbito regional (como no caso das políticas de desenvolvimento econômico local).

d) Aumento do poder de diálogo, pressão e negociação dos municípios: a articulação de um consórcio pode criar melhores condições de negociação dos municípios junto aos governos estadual e federal, ou junto a entidades da sociedade, empresas ou agências estatais. Com isso, vê-se fortalecida a autonomia municipal.

e) Aumento da transparência das decisões públicas: como as decisões tomadas pelos consórcios são de âmbito regional e envolvem vários atores, naturalmente elas se tornam mais visíveis, pois exigem um processo de discussão mais aprofundado em cada município e em termos regionais. Com isso, abre-se espaço para uma maior fiscalização da sociedade sobre a ação dos governos.

Além dos resultados positivos, Calderan (2013) chama a atenção para algumas desvantagens no processo de constituição de um consórcio público, entre eles: os interesses dos executivos municipais, de vários partidos políticos, até opositores, por vezes, deixam de lado a busca por uma solução por não saberem conviver em um ambiente suprapartidário. Exemplos, a sede do consórcio, o fortalecimento de um hospital regional.

No entanto, Calderan (2013) reforça a importância dos consórcios, na medida em que reduz os gastos e gerencia melhor os serviços, o planejamento orçamentário, bem como facilita a prestação de contas. Finalmente, estabelece relação saudável com os estados-membros e União para repasse de verbas. 
Já em 2005, Stucchi destacava que uma das vantagens é a possiblidade de se conseguir melhores preços por meio de grandes aquisições entre vários municípios. Aliás, essa parece ser uma grande força dos consórcios intermunicipais de saúde, o significativo aumento do poder de barganha de municípios de pequeno porte. O poder de associação traz para os envolvidos um canal aberto com instituições, indústrias e outras esferas de governo, tanto federal como estadual, aumentando seu poder de negociação.

\subsection{A experiência brasileira de Consórcios Intermunicipais}

A possibilidade legal de atuação associada entre municípios está presente no País desde o século XIX. É preciso salientar, no entanto, que, naquele momento, os municípios não tinham o status constitucional de entes federados e eram unidades administrativas dos estados-membros. Assim, todas as questões atinentes aos municípios eram disciplinadas pelas Constituições estaduais. A única menção aos municípios feita na Constituição da República dos Estados Unidos do Brasil, de 1891, está no art. 68, que diz: "os estados organizar-se-ão de forma que fique assegurada a autonomia dos municípios em tudo quanto respeite ao seu peculiar interesse".

Cunha (2004) destaca que as primeiras experiências de consórcios municipais aconteceram no Estado de São Paulo. Na década de 1960, foi criado o Consórcio de Promoção Social da Região de Bauru e, na década de 1970, o Consórcio de Desenvolvimento do Vale do Paraíba. Também em São Paulo foi constituído o consórcio intermunicipal de saúde, que posteriormente serviu de inspiração para um conjunto de outros municípios brasileiros - o Consórcio de Penápolis -, organizado em 1986.

Para Calderan (2013), com a promulgação da Constituição Federal, 1988, os municípios, na condição de entes federativos, adquiriram muitas responsabilidades, que antes eram somente do estado e da União. No processo de descentralização, os municípios assumiram a gestão de projetos de infraestrutura, saúde, educação, segurança, proteção e preservação ambiental, além de planos para desburocratizar as atividades econômicas e a prestação de serviços públicos, o que poderá causar desiquilíbrios nas finanças, por isso os consórcios surgem como uma alternativa para minimizar as dificuldades municipais.

Já a Lei n 11.107, de 2005 (BRASIL, 2005), instituiu as normas gerais de contratação de consórcios públicos e dá outras providências. Em seu art. $1^{\circ}$, consta:

Art. 1ํ- Esta Lei dispõe sobre normas gerais para a União, os Estados, o Distrito Federal e os Municípios contratarem consórcios públicos para a realização de objetivos de interesse comum e dá outras providências.

$\S 1^{0} \mathrm{O}$ consórcio público constituirá associação pública ou pessoa jurídica de direito privado.

$\S 2^{\circ} \mathrm{A}$ União somente participará de consórcios públicos em que também façam parte todos os Estados em cujos territórios estejam situados os Municípios consorciados.

$\S 3^{\circ}$ Os consórcios públicos, na área de saúde, deverão obedecer aos princípios, diretrizes e normas que regulam o Sistema Único de Saúde SUS. 
Scomparini e Zaninelo (2010) salientam que, no início, os consórcios intermunicipais de saúde eram unicamente de caráter privado, mas, segundo Neves e Ribeiro (2006), a sanção presidencial da Lei n. 11.107, em seis de abril de 2005, enfatizou a importância dos consórcios como mecanismo de governança regional, favorecendo novas soluções em gestão pública, normatizando, assim, de modo inédito no País, a figura de governo regional. Com isso, muitos consórcios constituídos inicialmente como privados iniciaram medidas para sua conversão em entes públicos.

Allebrandt (2011) salienta que, nos municípios interioranos de pequeno e médio porte, onde os cidadãos estão mais próximos dos tomadores de decisão, a participação da sociedade civil é uma questão crucial. Os mecanismos de eficiência coletiva ou social passam a ter maior relevância, pois o município não pode privilegiar as funções reguladoras em detrimento das de provisão de serviços nas áreas sociais, principalmente se considerarmos o aumento das carências sociais provocadas pela exclusão de grandes camadas da população.

Mas a realidade da grande maioria dos municípios brasileiros é a convivência com práticas e processos de gestão que estão mais próximas de modelos neopatriomanialistas ou burocráticos do que dos novos modelos: seja o gerencial, seja o societal, ou pelo menos convivendo com traços inscritos ao longo do continuum destes modelos. Paradoxalmente, estamos vivenciando uma verdadeira reinvenção do governo, especialmente pelo estabelecimento de novas formas de relacionamento entre a sociedade e o Estado, novos mecanismos de participação e democracia, novas formas de comunicação, mais democráticas e transparentes.

Para Freitas e Oliveira (2015), os consórcios de saúde constituem-se como uma ferramenta de participação social, que, por meio da instituição do Sistema Único de Saúde, ganharam contornos nesta área, sendo garantida sua existência na legislação, conforme se pode observar na Lei Orgânica de Saúde $n^{\circ} 8.080$, de 19 de setembro de 1990, que prevê em seu art. 10 que "Os municípios poderão constituir consórcios para desenvolver em conjunto as ações e os serviços de saúde que lhes correspondam".

Stucchi (2005) destaca, como exemplo o financiamento dos Consórcios Intermunicipais de Saúde - CISs, que se dá por meio de transferências diretas ou indiretas de recursos do Sistema Único de Saúde aos municípios. O financiamento em geral é composto de uma combinação de três fontes básicas: quotas dos municípios consorciados (definidas segundo critérios populacionais e ou utilização dos serviços); recursos provenientes diretamente do Sistema Único de Saúde e recursos provenientes das Secretarias Estaduais de Saúde.

Ainda, para Stucchi (2005), as configurações de oferta acabam por estimular os CISs, sendo uma delas decorrente da existência de um polo na microrregião que atrai a migração de pacientes dos municípios vizinhos. Outra situação observada é a da baixa oferta de serviços de maior complexidade tecnológica ou de especialistas médicos em uma área geográfica ampla. Nesse cenário, a formação de consórcios é favorecida, considerando-se a existência de uma fonte fixa de recursos do Sistema Único de Saúde associada aos gastos municipais. Quando os governos estaduais aportam recursos novos para estimular estas experiências, os consórcios formam-se como padrão dominante de regionalização da política de saúde. 


\section{Análise Resultados}

A pesquisa realizada na página do Confron$^{1}$ indica que o Consórcio Público Fronteira Noroeste é uma associação pública de municípios, de direito público interno e natureza autárquica, integrada pelos entes federativos, Municípios de: Alecrim, Alegria, Boa Vista do Buricá, Cândido Godói, Campina das Missões, Giruá, Dr. Maurício Cardoso, Horizontina, Independência, Nova Candelária, Novo Machado, Porto Lucena, Porto Mauá, Porto Vera Cruz, Santa Rosa, Santo Cristo, Salvador das Missões, São Pedro do Butiá, São Paulo das Missões, São José do Inhacorá, São Martinho, Senador Salgado Filho, Três de Maio, Tucunduva e Tuparendi, do Estado do Rio Grande Do Sul.

A entidade se caracteriza como ente da administração indireta de seus associados, regulamentada nos termos da Lei $n^{0}$ 11.107/2005 e Decreto $n^{0}$ 6.017/2007, ratificada por lei de cada ente participante, com atuação prioritária em dispor serviços de saúde - média e alta complexidade - bem como se propõe a atuação multifuncional, nos termos da permissividade da Lei e Contrato Constitutivo do Consórcio, credenciando a região da Fronteira Noroeste do Estado do Rio Grande do Sul com uma agência executiva regional, que tem por objetivo a promoção do desenvolvimento integral e sustentável da região de sua abrangência, com capacidade jurídica para planejamento, implementação e execução de políticas, projetos, ações e/ou programas de interesse público em todas as áreas da administração pública, junto a quaisquer esferas governamentais - União, Estado, Estatais - formando uma Mesorregião de 240.015 habitantes e $6.142 \mathrm{~km}^{2}$, com o território único da associação pública dos atuais 25 municípios.

O Consórcio surgiu no ano de 1994, objetivando ações conjuntas e gestão associada de serviços de saúde. Foi instituído inicialmente com o nome de Consórcio Distrital de Saúde - Codis. Seguiu obediente aos princípios norteadores da administração pública, focada na orientação de administração pública em geral, bem como dos termos do TCE-RS - Resolução $n^{\circ}$ 007/2002, com a regulamentação legal decorrente da Lei $n^{\circ} 11.107 / 2005$ e Decreto $n^{\circ}$ 6.017/2007, que regulamentou os consórcios públicos. A partir daí se projetaram estudos para consolidar uma agência pública multilateral, de capacidade ampliada. Em 2009, construiu-se, por decisão política regional, o protocolo de intenções em 22 de dezembro, que determinou a migração do Codis para constituir o Consórcio Público Fronteira Noroeste. Em julho de 2010, tornou-se realidade, após as edições das respectivas leis dos 25 municípios associados, formando uma agência executiva pública, com capacidade multilateral de direito público.

O Confron definiu os seguintes valores de atuação:

Celeridade - Uso racional do tempo em todas as fases de seus processos.

Credibilidade - Confiança que os jurisdicionados, organizações da sociedade civil, empregados, servidores e cidadãos em geral têm na atuação institucional do Confron.

Efetividade - o Confron adotará procedimentos sistêmicos visando a assegurar o cumprimento das decisões proferidas, instando as autoridades responsáveis a implementar as medidas delas decorrentes a fim de preservar o interesse público.

${ }^{1}$ www.cofron.rs.gov.br 
Ética - A conduta de suas ações deve buscar a verdade dos fatos, amparada na honestidade, moralidade, coerência e probidade administrativa.

Justiça - A atuação deve pautar-se na justiça, que consiste em conceder a cada um o que é seu, tratando a todos com a mais absoluta igualdade.

Organização - O Confron buscará a melhoria contínua dos seus processos, procedimentos e ambientes de trabalho, bem como a qualidade na prestação de serviços aos jurisdicionados, às organizações da sociedade civil, aos cidadãos, em geral, e aos seus funcionários, em particular.

Transparência - O Confron tornará públicas todas as suas decisões e seus atos de gestão.

O questionário foi encaminhada por e-mail, em janeiro de 2017, para um gestor do Confron, constituído por 16 questões. Na sequência, apresentam-se as respostas do gestor, que é graduado em Direito e atua como procurador jurídico na entidade desde 1997.

Segundo o gestor, nas respostas do questionário, apresenta a criação do Consórcio como decorrência da Lei 11.107/05 e do Decreto Federal nº.017/2007, que funciona com estrutura administrativa independente, com os respectivos órgãos consultivos e deliberativos.

Em relação à importância do Confron, destaca que a busca por parte dos municípios que integrarem o consórcio se dá pela necessidade da gestão associada nos serviços de saúde, reduzindo os custos operacionais e capacitando a oferta de volume de quantitativos. Destaca que as vantagens desse tipo de aglomeração representam um leque enorme de ações, conforme elenca a própria legislação que rege os consórcios.

Aponta o respondente do questionário que a grande centralidade do consórcio se dá pelo acesso a recursos públicos continuadamente, como negativo, a burocracia administrativa. Evidencia que a formação do consórcio foi necessária e imprescindível, porém, o funcionamento burocrático e os prazos sequenciais e contínuos são equiparados a qualquer outra gestão municipal.

O respondente aponta o planejamento do consórcio como um dos caminhos para resolver as dificuldades e desafios do Confron. Ainda reforça os serviços oferecidos, a contratualização de serviços de saúde de média e alta complexidade para os 25 municípios associados; a viabilização regional do Sistema SAMU; a viabilização regional do Sistema UPA; e, por fim, ser um fórum de debate e construção intergestores.

O respondente reforça a importância da contratação pelos municípios, que possibilita um melhor desempenho na formação dos custos, na área da saúde, em cada município, potencializando-os como associados do consórcio, usuário de uma estrutura operacional. Esse processo aponta para o planejamento, onde os benefícios e os custos são rateados anualmente entre os sócios do consórcio. Segundo o entrevistado, em média, é possível economizar uma proporção de 1/25 na estrutura operacional.

Mesmo tendo presente o planejamento, a pesquisa aponta que é possível qualificar mais a estrutura funcional do consórcio, que atualmente conta com três profissionais: um jurídico, uma contadora e uma escriturária. 
Em relação ao possível interesse em formar outros consórcios públicos, em outras áreas, destaca o respondente, que o Confron atende todas as demandas jurídicas possíveis de consorciamento de entes públicos em nível municipal.

Por fim, em relação às perspectivas estratégicas do Confron, destaca o respondente, a manutenção da legalidade das ações cotidianas no curto prazo, e no longo prazo, a manutenção das ações e pactos aprovados pelo Conselho de Prefeitos, bem como por novas ações de interesse do coletivo dos municípios associados.

Os questionários receberam respostas de três Secretarias Municipais de Saúde que são consorciadas no Confron. As questões foram similares às aplicadas pelo questionário ao gestor do consórcio, porém, ajustadas por conveniência, totalizando 13 questões abertas, também aplicadas em janeiro/2017. Na sequência, apresentam-se as respostas, sendo que se optou por identificar os respondentes apenas por uma letra, para preservar sua identidade, conforme acordado com eles.

O respondente da Secretaria Municipal de Saúde A é formado em curso técnico em Agricultura. Iniciou sua atuação profissional na Secretaria Municipal de Saúde no ano de 2000, na função de Diretor Administrativo, sendo que, em 2001, assumiu como Secretário de Saúde até 2016. Nesse período, participou de vários conselhos municipais, regionais e estaduais na área de saúde e outros. Salienta que o Confron já estava constituído e surgiu pela alta demanda de exames e procedimentos não oferecidos pelo SUS, bem como em função dos limites de especialidades oferecidas, as quais eram adquiridas com valores elevados, desafiando os prefeitos na busca de alternativas para atender e amenizar a demanda dos usuários e na troca de experiências regionais, considerando que na época existiam poucos consórcios constituídos.

O respondente destaca que o consórcio atende em parte à demanda regional, especialmente as especialidades ofertadas em nível de região desafiam o consórcio, por não ser possível conveniar por falta de profissionais. Destaca como vantagem, a agilidade na demanda dos usuários dos municípios, redução da fila na espera dos exames.

Em relação aos pontos mais relevantes (positivos e negativos), enfatiza o respondente, a constituição de uma empresa jurídica dos prestadores de serviços, que desvincula as obrigações trabalhistas dos conveniados, considerando que os municípios eram solidários na ocorrência de alguma ação trabalhista. Outro ponto relevante foi a abertura para profissionais e entidades de outras regiões possibilitando uma oferta maior de opções aos usuários de consultas, procedimentos, a busca de recursos públicos do SUS através do consórcio.

Em relação ao funcionamento do Confron, o respondente considera que a gestão do consórcio é muito concentrada no setor jurídico. Por mais que a assembleia seja soberana, deveria existir uma abertura maior para seus conveniados (municípios). Aponta ainda certa fragilidade no campo do conhecimento, especialmente quanto ao objetivo do consórcio, por parte de alguns gestores municipais (prefeitos).

Dentre as dificuldades, aponta o respondente, talvez nem tanto pelo modelo adotado pelo consórcio, mas pela resolutividade dos problemas de saúde da população, pelos prestadores dos serviços e solução de diagnósticos com muitos retornos. Ainda, uma atuação maior do controle interno do Confron, que deveria ser 
mais bem planejado, considerando que prestadores de serviços, além dos atendimentos, têm metas financeiras no final do mês a alcançar.

O respondente aponta que os diagnósticos de exames e procedimentos não ofertados no convênio pelos profissionais são realizados pelo Consórcio, que possui equipamentos para realiza-los. Na oferta de consultas, o acesso se torna fácil e os diagnósticos de exames não são auditados pela necessidade de realiza-los. Considerando a existência dos equipamentos, os profissionais solicitam os exames e procedimentos, mandam retornar aos municípios para autorizar, gerando despesas nem sempre necessárias, no entanto, aumenta a fatura do prestador.

Em relação aos custos de consorciamento no Confron, enfatiza que, dentro da demanda gerada e havendo um bom controle, é vantajoso e ajuda a reduzir a fila de espera. Além disso, é possível economizar em média $25 \%$ dos serviços ofertados em relação a outros convênios que os municípios realizam, principalmente nas consultas e exames.

A resposta no questionário, sobre o que, a seu ver, funciona, não funciona ou pode melhorar quanto à administração do consórcio, julga que o controle dos encaminhamentos com a implantação de sistema informatizado veio a contribuir nas agendas e informe quase que diário do financeiro demandado. O que deve ser melhorado é a agenda de muitos prestadores de serviços, os quais não oferecem uma agenda planejada aos municípios em quantitativo semanal. Significa que o município fica refém na oferta disponibilizada pelo prestador.

Sobre o interesse em formar consórcios públicos em outras áreas, respondeu que já existem os conselhos em outras áreas na regional, talvez menos atuantes que o consórcio de saúde. Em algumas áreas, como agricultura, o consórcio não deu certo.

Por fim, em relação às contradições para implementação de políticas regionais quanto aos consórcios municipais, o que impede o alcance dos resultados com maior efetividade do consórcio Confron, salienta que o grande problema é a resolutividade das ações desenvolvidas pelos prestadores de serviços e elevado número de retornos, geração de exames muito acima das normas estabelecidas na área da saúde e refém de profissionais praticamente com vínculos permanentes ( $O$ município tem paciente que está se tratando pelo menos 18 anos, sem alta até então).

Como perspectivas estratégicas de curto, médio e longo prazo na relação da Secretaria Municipal de Saúde e o Consórcio, espera-se que o Confron busque filiação a associação de consórcios do Rio Grande do Sul, considerando que foi um dos pioneiros nesta área para buscar alternativas em maior escala de interesse global, bem como a ampliação na busca de recursos públicos em benefício dos municípios.

A respondente da Secretaria Municipal de Saúde B não informou sobre sua formação e experiência profissional.

Sobre o surgimento da demanda pelo Confron, destaca que os municípios estavam com uma demanda reprimida na questão das especialidades média e alta complexidade e as referências SUS não estavam conseguindo ter resolutividade nas filas e demandas apresentadas. Então os prefeitos e secretários se reuniram e decidiram realizar contratos com prestadores de diferentes especialidades para agilizar o processo. Isso se deu principalmente pela dificuldade de profissionais 
cadastrados pelo SUS e referências SUS muito distantes dos municípios, bem como a fila.

A respondente considera que o consórcio é uma boa ferramenta para prestação de serviço, pela especialidade de referência SUS não pactuada e destaca a agilidade do sistema de saúde, como uma das vantagens de serem possíveis, através do consorciamento.

Dentre os pontos relevantes, salienta que é positiva a agilidade na média complexidade e prevenção. No campo negativo, destaca o custo para o município, que para ter resolutividade, acaba aumentando o custeio na média e alta complexidade, muitas vezes não recebendo do estado e da União, que deveriam custeá-las. Mesmo assim, considera a formação e funcionamento do consórcio como um instrumento ótimo de soluções.

A respondente destaca a dificuldade dos profissionais se cadastrarem no consórcio para o atendimento aos municípios. Considera o consórcio como uma alternativa legal, que ampara os municípios a realizar a compra de serviços não prestados pelo SUS. Toda e qualquer decisão do consórcio é discutido nas reuniões dos secretários, bem como dos prefeitos, então a participação dos municípios é muito atuante, então, vejo que o consórcio funciona muito bem. A parte administrativa é bem tranquila, a equipe fornece bastante suporte ao município.

Em relação ao interesse em formar consórcios públicos em outras áreas, destaca que também fazem parte do Consórcio Intermunicipal de Saúde das Regiões das Missões - CIS Missões, que realiza a compra de medicamentos. Lembra que há o Consórcio Intermunicipal de Saúde do Noroeste do RS - CISA, que ainda não participa, em função das especialidades, medicamentos, Centro Especializado Odontológico - CEO.

A questão sobre as contradições para implementação de políticas regionais, quanto aos consórcios municipais - o que impede o alcance dos resultados com maior efetividade do consórcio Confron, informa que hoje o consórcio possui uma abrangência e qualidade boa, entretanto, há a dificuldade dos profissionais e hospitais em quererem aderir aos consórcios.

Por fim, destaca a respondente, que as perspectivas estratégicas de curto médio e longo prazo do município, com o Confron, são de fortalecer cada vez mais sua atuação, com a ampliação de profissionais.

Outro respondente do questionário é formado em Administração, especialista em Gestão em Serviços e Sistemas de Saúde, mestre em Gestão Pública. Foi Secretário Municipal da Saúde de 2001 a 2009, e de 2009 a 2015. Atuou como Secretário Geral de Governo. Além disso, assumiu a $14^{\circ}$ Coordenadoria Regional da Saúde de Santa Rosa, a qual abrange 22 municípios.

Destaca que a demanda pelo consórcio surgiu devido à dificuldade dos municípios em contratarem serviços isoladamente, bem como de negociarem com os referidos profissionais, e que o município aderiu ao Confron devido à facilidade em contratar os serviços, pelos valores dos serviços menores do que encontrado nas clínicas e pela opção de vários profissionais, inclusive na mesma especialidade.

Considera que os consórcios públicos são uma boa ferramenta para prestação dos serviços públicos, por que é possível negociar coletivamente, possibilitando redução de valor do serviço buscado e pelo leque de opção de profissionais. 
Ainda, pela não necessidade de contratar o profissional, aumentando a despesa de pessoal e, muitas vezes, profissionais de uma determinada especialidade que não possuem demanda de serviços em um determinado município em função do quantitativo populacional, bem como a vantagem da redução do valor dos serviços.

Como ponto positivo relevante na construção do protocolo de intenções do Confron, cita a adesão de todos os municípios da região compreendida pela $14^{\circ} \mathrm{CRS}$, inclusive com adesão de municípios fora da região, como por exemplo: Giruá, São Paulo das Missões.

Em relação à formação e funcionamento do consórcio Confron, o respondente avalia que, devido ao aumento significativo de serviços ofertados e de profissionais cadastrados que prestam serviço por seu intermédio, faz-se necessária a profissionalização de sua gestão, com a capacitação de seu quadro de servidores, sendo a falta de gestão profissional uma das dificuldades encontradas no modelo adotado pelo consórcio.

Sobre os custos do consorciamento, julga o respondente como vantajoso, as negociações dos serviços de forma coletiva, que reduzem os valores, assim como a taxa de custo fixo faz com que o servidor municipal não tenha necessidade de ficar ligando ao profissional e negociar toda vez que busca um determinado serviço. Por isso, avalia que é possível economizar, em média, $25 \%$, dependendo do serviço e do profissional, pois se há uma demanda significativa de um determinado serviço, porém o número de profissional é reduzido, provavelmente a redução seja menor.

Destaca também que é necessário profissionalizar a gestão e melhorar o sistema de informática para possibilitar a migração dos dados gerados no sistema do Confron para os municípios consorciados.

Em relação ao interesse em formar consórcios públicos em outras áreas, houve a tentativa de um em máquinas rodoviárias, porém não teve sucesso devido à necessidade ser, em muitos casos, em períodos concomitantes.

O respondente não identifica nada que possa dificultar a implantação de políticas regionais de maneira consorciada.

E, para finalizar, destaca como perspectivas estratégicas do município com o Confron: de curto prazo, o acesso aos serviços já existentes; em médio prazo, a ampliação de novos serviços; em longo prazo, o cadastramento e o acesso de recursos da esfera federal para possibilitar a realização de procedimentos cirúrgicos junto a hospitais.

Outra respondente do questionário é bacharel em Engenharia Mecânica e atua na Secretaria de Saúde desde 2013, na função de Agente Administrativa, responsável pela gestão e planejamento financeiro da Secretaria.

Destaca que a demanda pelo Confron surgiu, basicamente, da necessidade de oferecer serviços aos munícipes, os quais não são disponibilizados em nossa instituição, pelo fato de ser um hospital de pequeno porte. A justificativa para o município consorciar-se foi em função de que o Confron oferece serviços de média complexidade na saúde e a Unidade Básica de Saúde do município atende somente à demanda de atenção básica. Julga que tratar diretamente com os profissionais não é fácil, pois o pagamento de serviços realizados pelo município é um tanto quanto burocrático. 
A respondente reforça que alguns profissionais se negam a realizar atendimentos para prefeituras e a utilização do Consórcio facilita muito o acesso. Assim, os consórcios fazem um meio campo importante entre os prestadores de serviços e os usuários. Há uma lista de profissionais que atendem pelo Confron, sendo financeiramente mais viável e garantindo o acesso da população, que se dá por intermédio da Central de Regulação do município.

A vantagem destacada pela respondente é o baixo custo ao município. De positivo, considera que a demanda e a oferta de serviços foram analisadas, e salienta que os pontos negativos baseiam-se apenas na carência de certos profissionais que não são ligados ao consórcio, principalmente nas áreas psiquiátrica e endócrina.

Em relação à formação e funcionamento, considera satisfatória. Porém, se houvesse maior oferta de serviços, poderia ser melhor ainda. Além disso, os custos de consorciamento são muito vantajosos.

A economia também é outro aspecto que justifica a importância do Confron. Como exemplo, uma consulta cardiológica que custa $\mathrm{R} \$ 250,00$ pelo particular, e utilizando o Confron, custa $\mathrm{R} \$$ 40,00 ao município.

A administração tem se mostrado satisfatória, não há registro de qualquer problema entre o consórcio e o município.

A questão sobre o interesse em formar consórcios públicos em outras áreas, a respondente afirma que, a princípio, não existe esta possibilidade.

Considera que as contradições para implementação de políticas regionais quanto aos consórcios municipais e que impede o alcance dos resultados com maior efetividade do consórcio Confron é a carência de profissionais. Por isso, as perspectivas estratégicas de curto, médio e longo prazo do município com o Confron é a ampliação do número de especialidades ofertadas, tanto na questão de profissionais quanto de serviços.

\section{Considerações Finais}

O estudo buscou compreender o funcionamento do Confron, a partir do ponto de vista da gestão do Consórcio, bem como dos entes públicos consorciados. A partir das respostas presentes no questionário, verificamos a sua importância e a sua abrangência, tanto pelo número de municípios que o integram como para o desenvolvimento da região, especialmente na qualidade de vida da população.

Tanto o gestor quanto todas as secretarias de saúde destacam que o surgimento se deu para sanar uma lacuna relacionada à dificuldade, principalmente dos pequenos municípios, em proporcionar serviços e profissionais de saúde em especialidades de média e alta complexidade. Outro aspecto que foi apontado pelos questionários foi a economia em torno de $25 \%$ para os municípios do consórcio. Isso se dá pela possibilidade de negociação coletiva, bem como pela ampliação de alternativas tanto de profissionais quanto de serviços.

Dentre as possibilidades de melhoria está a necessidade da ampliação da gestão do consórcio, tanto em número de profissionais quando no processo como um todo, buscando a profissionalização. Nesse sentido, a qualificação da matriz administrativa implicará no fortalecimento das ações e no aumento da confiabilidade pelos consorciados. 
Em relação à ampliação da atuação consorciada para outras áreas, as respostas indicam as experiências e a existência de outros consórcios, porém, o Confron se destaca pela adesão de todos os municípios da região de abrangência da coordenadoria regional, inclusive com a participação de municípios de outras coordenadorias, o que confirma a sua consolidação como um diferencial em termos de cooperação em políticas públicas, impactando positivamente para com a população de cada município e o desenvolvimento da região.

\section{REFERÊNCIAS}

ALLEBRANDT, S. L.; RETAMOSO, A. S.; BENSO, A.; LEITE, A. G. da C.; OURIQUE, S. L. Participação social no planejamento do desenvolvimento e na elaboração dos orçamentos públicos nos municípios do Noroeste Colonial gaúcho.

Desenvolvimento Regional em debate Ano 1, n. 1, Universidade do Contestado, dez. 2011.

ALVES-MAZZOTTI, A. J.; GEWANDSZNAJDER, F. O método nas ciências naturais e sociais: pesquisa quantitativa e qualitativa. São Paulo, Pioneira, 1998.

ANDRADE, M. C. A questão do território no Brasil. São Paulo: Hucitec; Recife: IPESPE, 1995.

BERGOC, G. J. Associações de Municípios do Estado do Paraná: cooperação e planejamento para o desenvolvimento regional. São Paulo, 2001. Dissertação (Mestrado em Estruturas Ambientais Urbanas) - FAU/USP.

BIGATON, I. C.; MAIA, C. M. Consórcios públicos intermunicipais: a cooperação em prol do desenvolvimento regional. $3^{\circ}$ SEDRES: Blumenau/SC, 2016.

BRASIL. Constituição (1891) Constituição da República dos Estados Unidos do Brasil. Rio de Janeiro, 1891. Disponível em http://www2.camara.leg.br/legin/fed/consti/1824-1899/constituicao-35081-24fevereiro-1891-532699-publicacaooriginal-15017-pl.html Acesso em 19 de junho de 2018.

BRASIL. Constituição (2005) Disponível emhttp://www2.camara.leg.br/atividadelegislativa/legislacao/Constituicoes_Brasileir as/constituica02005.html Acessado em 21 de junho de 2018.

BRASIL. Constituição (1988). Disponível em http://www2.camara.leg.br/atividadelegislativa/legislacao/Constituicoes_Brasileiras/ constituicao1988.html Acesso em 25 de junho de 2018.

BRASIL Lei nº 8.080, de 19/09/1990: Sistema Único de Saúde (SUS) Disponível http://www.editorasolucao.com.br/media/materialcomplementar/guiadoconcurso/ UNCISAL/09-leis-8080-8142+LC-141+9394.leg.pdf Acesso em 25 de junho de 2018. 
CALDERAN, T. B. Consórcio público intermunicipal de gerenciamento de resíduos sólidos domésticos: um estudo de caso. Dissertação de Mestrado em Ambiente e Desenvolvimento, UNIVATES, 2013.

COLLIS, J.; HUSSEY, R. Pesquisa em Administração: um guia prática para alunos de graduação e pós-graduação. Trad. Lucia Simonini: Porto Alegre, Ed. Bookman, $2^{\mathrm{a}}$ Ed. 2005 .

Consórcio Público Fronteira Noroeste (Cofron). Disponível em www.cofron.rs.gov.br. Acessado em 19 janeiro, 2018.

CUNHA, R. E. Federalismo e relações intergovernamentais: os consórcios públicos como instrumento de cooperação federativa. Revista do Serviço Público, Ano 55, ${ }^{\circ}$ 3, Jul-Set de 2004.

DALLABRIDA, V. R.; ZIMMERMANN, V. J. Descentralização na Gestão Pública e Estruturas Subnacionais de Gestão do Desenvolvimento: o papel dos Consórcios Intermunicipais. Revista Brasileira de Gestão e Desenvolvimento Regional, Taubaté (SP), v. 5, n. 3, set./dez./2009.

FRANTZ, W. Sociologia do desenvolvimento. ljuí: Ed. Unijuí, 2010. (Coleção educação a distância. Série livro-texto)

FREITAS, B. R.; OLIVEIRA, A. R. Avaliação dos Consórcios Intermunicipais de Saúde da Zona da Mata Mineira: uma análise sob a ótica dos gestores de Saúde. HOLOS IFRN, Ano 31, Vol. 3, 2015.

LAKATOS, E. M.; MARCONI, A.M. Fundamentos de metodologia científica. São Paulo: Atlas 1986.

LIMA, A.P.G. Os Consórcios Intermunicipais de Saúde e o Sistema Único de Saúde. Cadernos de Saúde Pública, Rio de Janeiro, v.16, n. 4, p.985-996, 2000. Disponível em. Acessado em janeiro de 2018.

LOVATO, A. Metodologia da pesquisa. Três de Maio, SETREM, 2013.

RIBEIRO, J.; COSTA, N. do R. Regionalização da assistência à saúde no brasil: os consórcios municipais no sistema único de saúde (SUS). Planejamento e Políticas Públicas - IPEA, n²22, Dez. de 2000.

SAUSEN, J. O. Gestão estratégica, competitividade e desenvolvimento: um olhar a partir das suas inter-relações. In: SIEDENBERG, D. R. (Org.). Desenvolvimento Sob Múltiplos Olhares. Ijuí: Unijuí, 2012. p. 207-267.

SCOMPARINI, A. K.; ZANINELO, G. Análise da gestão pública de um consórcio intermunicipal de saúde da Região Noroeste do Paraná. Semana de Estudos Contábeis e de Administração - FAFIPA, 2010, ISSN 2178-5007. 
SIEDENBERG, D. R. (Org.). Desenvolvimento Sob Múltiplos Olhares. ljuí: Unijuí, 2012.

STUCCHI, M. L. R. Consórcios intermunicipais de saúde no Estado de São Paulo. Revista Administração Saúde: 7(29): 118-126 out.-dez. 2005.

TENÓRIO, F. G. Cidadania e desenvolvimento local: casos brasileiros. IX Congreso Internacional del CLAD sobre la Reforma del Estado y de la Administración Pública, Madrid, España, 2 - 5 Nov. 2004.

Nelson José Thesing. Doutor em Integração Regional. Professor do Departamento de Ciências Administrativas, Contábeis, Econômicas e da Comunicação. Integra o Corpo Docente do Programa de Pós-Graduação Stricto Sensu em Desenvolvimento Regional e faz parte do Grupo Interdisciplinar de Estudos em Gestão e Políticas Públicas, Desenvolvimento, Comunicação e Cidadania - GPDeC - Unijuí. nelson.thesing@unijui.edu.br

Sérgio Luis Allebrandt. Doutor em Desenvolvimento Regional (UNISC), docente do programa de mestrado e doutorado em Desenvolvimento Regional (UNIJUí). allebr@unijui.edu.br

Mauro Alberto Nuske. Doutorando em Desenvolvimento Regional (UNIJUí), docente na Faculdade Três de Maio (SETREM). mauronuske@setrem.com.br

Nedisson Luis Gessi. Doutorando em Desenvolvimento Regional (UNIJUÍ), docente na Fundação Educacional Machado de Assis (FEMA), E-mail: nedisson@fema.com.br 